Revista de Derecho

Universidad Católica del Norte

Sección: Estudios

Año 18 - No 1,2011

pp. $85-118$

\title{
LOS CRITERIOS DE INTERÉS CONTRACTUAL POSITIVO Y NEGATIVO EN LA INDEMNIZACIÓN DE PERJUICIOS DERIVADA DE RESOLUCIÓN CONTRACTUAL
}

\author{
JUAN IGNACIO CONTARDO GONZÁLEZ*
}

RESUMEN: El presente trabajo propone analizar la indemnización de perjuicios en caso de resolución por incumplimiento bajo los criterios indemnizatorios de interés positivo y negativo. Se intenta demostrar que en el caso de resolución por inejecución el interés contractual indemnizable en el Código Civil es el interés positivo.

PALABRAS CLAVE: Responsabilidad civil contractual - resolución por incumplimiento - indemnización de perjuicios - interés contractual positivo - interés contractual negativo.

\section{THE CRITERION OF POSITIVE AND NEGATIVE CONTRACTUAL INTEREST IN THE COMPENSATION FOR DAMAGES DERIVED FROM A CONTRACTUAL RESOLUTION}

ABSTRACT: This article analyzes damage compensation in case of breach of contract resolution under the positive and negative indemnity interest criteria. It intends to prove that in case of resolution for nonperformance the compensating contractual interest in the Civil Code is the positive interest.

KEY WORDS: contract liability - breach of contract resolution damage compensation - positive contractual interest - negative contract interest.

La distinción entre interés contractual positivo y negativo como criterio de avaluación del daño indemnizable por incumplimiento de contrato parece provenir del common law. Ella aparece en el clásico artículo

Abogado. Licenciado en Ciencias Jurídicas por la Universidad Adolfo Ibáñez (CHILE). Alumno regular del Programa de Doctorado en Derecho de la Universidad de los Andes (Chile). Correo electrónico: jicontardo@uandes.cl.

Fecha de recepción: 23 de noviembre de 2010

Fecha de aceptación: 9 de marzo de 2011. 
de Lon Fuller y William Perdue, The reliance interest in contract damages, publicado entre los ańos 1936 y 1937 en Yale Law Journal', basada en la distinción que había hecho para la responsabilidad precontractual Rudolf von Ihering ${ }^{2}$.

Fuller y Perdue distinguen tres clases de intereses indemnizatorios por incumplimiento de contrato: El expectation interest, o interés contractual positivo; el reliance interest, o interés contractual negativo; y el restitution interest o interés restitutorio.

Fuller y Perdue estiman que los perjuicios basados en el expectation interest consisten en "colocar al demandante en una posición similar como si el demandado hubiera cumplido su promesa" ${ }^{3}$. El reliance interest tiene por "objeto colocarlo [al demandado] en una posición similar como lo estaba antes de que la promesa se hubiese celebrado" 4 . Por último, el interés restitutorio tiene por objeto evitar que el contratante incumplidor obtenga una ganancia o beneficio por el efecto de la inejecución del contrato ${ }^{5}$.

Tal como se puede apreciar, los conceptos de interés positivo y negativo permiten determinar cuál es la medida del daño contractual indemnizable. Dicho de otra forma, en qué momento el juez debe colocar su

Fuller, Lon / Perdue, William (1936-1937). "The reliance interest in contract damages". Yale Law Journal, vol. 46, pp. 52-96 y 373-420. Del common law, la distinción pasa a los derechos de tradición codificada: Genicon, Thomas (2007). La resolution du contrat pour inexécution. Paris: L.G.D.J., p. 722; Laithier, Ives-Marie (2007). Étude comparative des sanctions de l'inexecution du contrat. Paris: L.G.D.J., p. 158; Pantaleón, Fernando (1989). "Resolución por incumplimiento e indemnización". Anuario de Derecho Civil, vol. 42 $\mathrm{N}^{\circ}$ 4, pp. 1143-1168, pp. 1148-1149. A pesar de las diferencias entre los sistemas resolutorios del common law y de tradición continental, las referencias al sistema anglosajón se justifican porque en ambos casos se concede la facultad del acreedor para resolver o terminar el contrato (o bien, solicitarlo por vía judicial), y la consecuente posibilidad de demandar por perjuicios: Treitel, G. H. (1995). The law of contract. London: Sweet \& Maxwell, pp. 762 y ss.; Farnsworth, E. Allan (2004). Contracts. 4a ed. New York: Aspen Publishers, pp. 562 y ss.

2 Ihering es citado expresamente: Fuller / Perdue (1936-1937) notas 54 a 56. Según IheRING la base de expectativas razonables que genera la no celebración del contrato, permitiría accionar por perjuicios en sede contractual. Los daños no se centrarían en lo que le hubiera reportado al futuro acreedor el cumplimiento de la promesa, sino en los daños relativos a gastos y expensas con ocasión de la celebración del contrato. Lo que configura la indemnización del interés negativo o de confianza. Al respecto, véase Zimmermann, Reinhard (1996). The law of obligations. New York: Oxford University Press, pp. 244-245; Barrientos ZamoRANo, Marcelo (2008). Daños y deberes en las tratativas preliminares de un contrato. Santiago: LegalPublishing, pp. 8-14.

3 Fuller / Perdue (1936-1937) 54 [Traducción libre del autor]. Dice el texto original: "Here our object is to put the plaintiff in as good a position as he would have occupieds had the defendant performed his promise".

$4 \quad$ Fuller / Perdue (1936-1937) 54 [Traducción libre del autor]. Dice el texto original: "Our object is to put him in as good position as he was in before the promise was made".

5 En el presenten estudio solo se estudiarán los criterios de interés positivo y negativo, dejando de lado el estudio del interés restitutorio por exceder los límites de esta exposición. 
mirada para efectos de determinar el perjuicio contractual: si al momento de la celebración o del incumplimiento del contrato.

En términos generales, la concepción que es favorable a la indemnización del interés positivo es concordante con una cierta visión funcionalista del contrato. Esto es, los daños resultantes de la infracción del contrato guardan correspondencia con la esperanza que se tenga sobre la utilidad que la ejecución del contrato representa para el acreedor ${ }^{6}$. Una óptica funcionalista permite señalar que a partir del incumplimiento sería posible medir la expectativa de cumplimiento en dinero.

Por el contrario, el interés negativo como criterio de avaluación de los dańos contractuales se muestra útil en una esfera de la ineficacia del contrato $^{7}$. El acreedor, al buscar la liberación del contrato por el evento de la resolución (o efecto liberatorio), no podría, en principio, reclamar los perjuicios por la expectativa de cumplimiento, puesto que su interés actual en el contrato se reduce a la resolución, esto es, a la extinción de la relación contractual. De esta suerte, los perjuicios que podría cobrar solo serían aquellos que sufre con ocasión de la celebración del contrato, principalmente los gastos que implicó la oportunidad de contratar.

En el presente trabajo se estudiará la aplicación de estos criterios indemnizatorios en la resolución por incumplimiento en el derecho nacional. El artículo 1489 del Código Civil ${ }^{8}$, luego de consagrar los remedios de cumplimiento forzado y resolución, contempla expresamente una acción indemnizatoria que podría dar lugar tanto al resarcimiento del interés positivo como del interés negativo.

Siguiendo lo expuesto, se podría decir que si el acreedor solicita el cumplimiento, tendría que ser indemnizado del interés positivo; en cambio, si solicita la resolución, del interés negativo.

Sin embargo, en la resolución ambas esferas, la de la función del contrato y la de su ineficacia, se presentan. Por una parte, el acreedor busca la ineficacia del contrato, y por la otra, la indemnización de los perjuicios resultantes del incumplimiento. Se produce, entonces, una tensión entre los efectos de la resolución y la expectativa de cumplimiento. Por lo tanto, se hace necesario determinar si lo indemnizable se refiere a la confianza depositada en la celebración del contrato, o bien, en la expectativa de que será cumplido por la contraparte.

LAITHIER (2007) 161-162

GENicon (2007) 724.

En lo sucesivo, las referencias normativas en que no se exprese un preciso cuerpo legal, corresponden al Código Civil chileno. 
Los autores nacionales no han tratado directamente el problema', pese a que está presente en la práctica judicial. Asimismo, al acreedor no le resulta indiferente la aplicación de estos criterios indemnizatorios. En las páginas que siguen, defenderemos la posibilidad de que en sede de resolución sería posible fundar la acción de perjuicios en el interés positivo o de expectativa.

A falta de tratamiento en el medio nacional, en el capítulo siguiente se estudiará la discusión que se ha presentado en la doctrina comparada sobre el interés indemnizable. Para luego, en el capítulo final, examinar el problema en el Código Civil chileno.

\section{2) LA DISCUSIÓN EN DOCTRINA COMPARADA SOBRE EL INTERÉS CONTRACTUAL PROTEGIDO EN LA RESOLUCIÓN POR INEJECUCIÓN}

Como se ha señalado, los criterios de daño al interés positivo o daño al interés negativo son aplicables a la resolución por inejecución, Sin embargo, la doctrina comparada no es pacífica en determinar cuál es el interés indemnizable.

En el presente capítulo expondremos cuáles son los principales argumentos que se han esgrimido para defender una u otra opción.

\section{(2.1.) ARGUMENTOS QUE SOSTIENEN LA RESARCIBILIDAD DEL INTERÉS NEGATIVO}

(a) En los sistemas de tradición europea continental ciertos autores estiman que, frente a la retroactividad de la resolución del contrato ${ }^{10}$, el interés indemnizable es el interés negativo. Para ellos, la pérdida de efectos del contrato implica que el daño se encuentra al momento del perfeccionamiento del contrato y no en la inejecución del mis$\mathrm{mo}^{11}$. Para estos autores, la indemnización de perjuicios en este caso es muy similar o prácticamente idéntica a un caso de culpa in contra-

9 La distinción entre interés positivo y negativo se tiene en cuenta en la reparación de los daños por responsabilidad precontractual: por todos, BARros Bourie, Enrique (2007). Tratado de responsabilidad extracontractual. Santiago: Editorial Jurídica de Chile, pp. 1006-1008.

10 Anota Palazón que en derecho codificado predomina el modelo de resolución retroactiva: fundamentalmente Francia (artículo 1143), Bélgica (artículo 1143), Italia (artículo 1543) y España (artículo 1124, todos de su respectivo Código Civil): Palazón Garrido, María Luisa (2009). "La resolución del contrato como medio de tutela en caso de incumplimiento". En Sánchez Lorenzo, Sixto (coord.): Derecho contractual comparado. Madrid: Civitas, pp. 769-820, pp. 809-813.

11 Véase los autores italianos y franceses citados por MéLICH-Orsini, José (2007). La resolución del contrato por incumplimiento. $3^{\text {a }}$ ed. Caracas: Academia de Ciencias Políticas y Sociales, pp. 390-391, especialmente notas 2 y 3. Así también lo ha resuelto alguna jurisprudencia 
hendo. Desde este punto de vista, la indemnización del interés negativo sería la forma más eficaz de proteger la confianza generada por la promesa empeñada en la celebración de un contrato ${ }^{12}$.

(b) Hay autores que se centran en el valor que el ordenamiento jurídico le confiere a la palabra empeñada. Así, Atiyah apunta que el Derecho no debería proteger la expectativa de cumplimiento de los contratos, puesto que el deudor se encontraría en la libertad de cumplir o no cumplir. De tal manera que, pudiendo cambiar de parecer, no tendría por qué responder por la expectativa de cumplimiento ${ }^{13}$.

(c) Así, consecuencialmente, se ha señalado que el interés contractual negativo implicaría romper con el principio de la fuerza obligatoria del contrato, por lo menos en su noción fundamental, que supone el cumplimiento del contrato en su totalidad, precisamente por la extinción del contrato ${ }^{14}$.

(d) También, autores anglosajones han discutido el rol del Estado en el cumplimiento de los contratos. Se ha sostenido, apoyando la indemnización del interés negativo, que el Estado (a través de la ley y de la interpretación judicial) tomaría el rol único de protección de la propiedad del contratante diligente (o de evitar la disminución patrimonial del acreedor producto del incumplimiento) ${ }^{15}$. Por tanto, la

argentina: véase el voto del juez Greco en IBáŃEz, Carlos (2006). Resolución por incumplimiento. $1^{\text {a }}$ reimpresión. Buenos Aires: Astrea, p. 331; Trigo Represas, Félix / López Meza, Marcelo (2005). Tratado de la responsabilidad civil, Buenos Aires: La ley, t.1, p. 455, en especial nota 300 .

12 Fuller / Perdue (1936-1937) 62; Hudec, Robert (1984). "Restating the 'reliance interest"”. Cornell Law Review, vol. 67, pp. 704-734, p. 712. También, desde esta óptica podría entenderse que el resarcimiento del interés negativo es una forma de resolver los casos difíciles cuando no hay certeza, sobre todo, del daño futuro. Macaulay, Stewart (1991). "The reliance interest and the world outside the law schools' doors". Wisconsin Law Review, 1991, pp. 247-291, 274-276; Trimarchi, Pietro (2002). "Interesse positivo e interesse negativo nella risoluzione del contratto per inadempimento". Rivista di dirrito civile, vol. 48 $\mathrm{N}^{\circ}$ 5, 637-648, pp. 647-648 (debe tenerse en consideración que Trimarchi es partidario de la indemnización del interés positivo, salvo caso de imposibilidad de prueba).

13 Aттуaн, P.S. (2001). "Contracts, Promises and the Law of Obligations". En Atiyha, P.S.: Essays on contract. New York: Oxford University Press, pp. 10-56, p. 33. Aтryah sostiene que durante la última parte del siglo XIX y el siglo XX (hasta la conclusión de su obra The rise and fall of freedom of contracts) se ha producido un deterioro de los principios contractuales. Uno de ellos es el de la fuerza obligatoria del contrato o "santidad de las promesas" (sanctity of promises). Concluye el autor que, a pesar del mentado principio, que el deudor puede liberarse del cumplimiento de los contratos sin existir un reproche moral por ello. El reproche moral al incumplimiento de la obligación impondría una sanción equivalente a pagar los perjuicios por la expectativa. AтіYAн, P.S. (2003). The rise and fall of freedom of contracts. New York, Oxford University Press, pp. 652-659.

14 Aтryah, P.S. (2003). Promises, morals and law. New York: Oxford University Press, p. 17.

15 SMITH, Stephen (2001). "The reliance interest in contract damages in Contract Damages' and the Morality of Contract Law", Issues in Legal Scholarship. Disponible en http://www. bepress.com/ils/issl/artl, en línea [fecha de visita 13 de octubre de 2010], pp. 30-31. 
función de cumplimiento e incumplimiento de los contratos debería ser entregada a los particulares ${ }^{16}$.

(e) Por otro lado, se ha sostenido que el criterio de previsibilidad de los daños (forseeability) ordenaría indemnizar solo aquellos derivados del interés negativo, puesto que estos derivarían de la causa próxima de la inejecución del contrato. De esta suerte, los daños que cubriría el interés positivo tendrían como causa remota y no directa el incumplimiento del contrato ${ }^{17}$.

(f) Desde este punto de vista, la indemnización del interés negativo sería más adecuada al requisito de la certeza de los dańos ${ }^{18}$. En este sentido, las actuales formas de celebración de los contratos (por adhesión o a través de condiciones generales de la contratación) en que no existe propiamente negociación solo permitirían indemnizar el interés negativo, ya que no es posible dar cuenta a la otra parte de los posibles efectos perniciosos que un incumplimiento del contrato traería aparejado para la otra parte ${ }^{19}$.

(g) Otro argumento que se ha proporcionado consiste en sostener que la elección potestativa de la resolución del contrato implica una renuncia al interés positivo, puesto que si verdaderamente el contratante diligente estuviera interesado en su propio interés en la prestación hubiere elegido el cumplimiento del contrato con indemnización de perjuicios ${ }^{20}$. Así, se ha sostenido que si bien teóricamente las restituciones mutuas prevenidas en la resolución por inejecución podrían ser compatibles con la indemnización del interés positivo, se señala que ello es técnicamente imposible. La elección de la resolución y la consecuente restitución al acreedor de la cosa hacen inadmisible pensar que podría reclamarse lo que le hubiera reportado el cumplimiento del contrato en circunstancias que la titularidad de la cosa vuelve en manos del acreedor ${ }^{21}$.

16 Fuller, Lon (1941). "Consideration and form". Columbia Law Review, vol. 41, pp. 799824, pp. 806-809.

$17 \quad$ Fuller / Perdue (1936-1937) 85-88.

18 Rakoff, Todd, (1991). "Fuller and Perdue's the reliance interest as a work of legal scholarship”. Wisconsin Law Review, 1991, pp. 203-246, p. 212.

19 Stawson, W. David (1990). "The role of reliance in contracts damages". Cornell Law Review, vol. 76, pp. 197-237, p. 207. Según Randy Barnett el interés positivo solo se aplica a las promesas en las que va envuelta la consideration que supone negociación. BARNETT, Randy (1984). "Contract Scholarship and the Reemergence of Legal Phylosophy". Harvard Law Review, Vol. 97, pp. 1223-1245, p. 1241.

20 Pinna, Andrea (2007). La mesure du préjudice contractuel. Paris: L.G.D.J., pp. 367-369; Di Majo, Adolfo (2003) Problemi e metodo del diritto civile. La tutela civile dei diritti. Milano: Giuffrè editore, pp. 239-240

21 PinNa (2007) 453-454. 
(h) La indemnización del daño extrapatrimonial, que la jurisprudencia contemporánea tiende a aceptar, sería más conforme al interés negativo que a la expectativa de cumplimiento ${ }^{22}$.

(i) Finalmente, se arguye que la indemnización del interés negativo sería conforme a un principio de justicia correctiva puesto que ella se basaría en la pérdida actual que ha sufrido el contratante diligente ${ }^{23}$ y que, en cambio, la indemnización del interés positivo se fundamentaría en la justicia distributiva, ya que garantizaría el beneficio esperado, más que compensarlo por la pérdida sufrida. Al Derecho privado de los contratos solo le correspondería resolver problemas de justicia correctiva y no de justicia distributiva, que son más propios del derecho público ${ }^{24}$.

\section{(2.2.) ARGUMENTOS QUE SOSTIENEN LA RESARCIBILIDAD DEL INTERÉS POSITIVO}

(a) Contestando el argumento de que la resolución alcanzaría con efectos retroactivos a su indemnización consecuencial, se señala que la resolución no opera con efectos retroactivos absolutos. Desde este punto de vista, los perjuicios derivan del incumplimiento y no de la no celebración del contrato ${ }^{25}$. En el único campo que tendría verdadera cabida la retroactividad de la condición sería en materia de restituciones mutuas ordenadas por la ley ${ }^{26}$, pero que en ningún caso serían incompatibles con la indemnización de perjuicios ${ }^{27}$.

22 Macaulay (1991) 276-281; Rakoff (1991) 241-242; Genicon (2007) 725.

23 Fuller / Perdue (1936-1937) 56.

24 Fuller / Perdue (1936-1937) 56-57. Sobre la noción de justicia correctiva como elemento de análisis de la noción de justicia que involucra el derecho privado, Weinrib, Ernest J. (1995). The idea of private law. Cambridge: Harvard University Press, pp. 56-83.

25 De Cupis, Adriano (1975). El daño. Traducción de Martínez Serrión, Ángel. Barcelona: Bosch, p. 359; Díez-Picazo, Luis (2008). Fundamentos del Derecho Civil Patrimonial. Madrid: Civitas, t. II, p. 727; IbáÑez (2006) pp. 336-337; Genicon (2007) 744-746; Mélich-Orsini (2007) 391-392; Pantaleón (1989) 1152 y ss.; Pantaleón, Fernando (1993). "Las nuevas bases de la responsabilidad contractual". Anuario de Derecho Civil, vol. $46 \mathrm{~N}^{\circ} 4$, 1993, pp. 1719-1746, pp. 1734-1735.

26 Pantaleón (1989) 1154.

27 Espinar es de una opinión intermedia. Este autor propone que a partir del artículo 1124 del Código Civil español (el equivalente a nuestro artículo 1489) se podría afirmar que contiene implícitamente una opción para el acreedor entre elegir una resolución con efecto retroactivo (que involucra la extinción del contrato) con la consecuente indemnización del interés negativo; y una resolución no retroactiva (que involucra solamente la extinción de la obligación, no del contrato) que permitiría la indemnización del interés positivo. EspiNar Lafuente, Francisco (1969). "Resolución e indemnización en las obligaciones recíprocas", en AA.VV.: Estudios de Derecho Civil. En honor del profesor Castán Tobeñas, Pamplona, Ediciones Universidad de Navarra, 1969, t. 2, pp. 150-153. 
(b) Sobre la libertad del deudor de despojarse de la palabra empeñada, Fried contesta a Atiyah, señalando que, precisamente, el deudor debe hacerse responsable por la expectativa que generó en ella ${ }^{28}$.

(c) Sobre el rol del Estado en el cumplimiento de los contratos, se ha señalado que este debería tomar un rol preponderante forzando el cumplimiento de los contratos y estableciendo indemnizaciones que permitan substituir de alguna forma el daño causado por el incumplimiento del contrato desincentivando la voluntaria inejecución contractual ${ }^{29}$. De tal suerte que, ante un incumplimiento de contrato, la imposibilidad de la obtención en una posición contractual de cumplimiento sería un atentado al derecho de propiedad mismo ${ }^{30}$.

(d) Se ha fundamentado, para sostener la resarcibilidad del interés positivo, que desde el punto de vista del daño mismo, aun con la desaparición retroactiva del contrato (si es que verdaderamente se produjese) el daño se mantiene y se perpetuaría en el tiempo ${ }^{31}$.

(e) Se ha agregado que el resarcimiento del interés negativo produce una asimetría entre la parte incumplidora y el contratante diligente puesto que resalta la expectativa de ganancia de la parte demandada por sobre las pérdidas que sufre la parte demandante. El interés positivo protege los intereses de ambas partes de forma simétrica ya que garantizaría la expectativa de cumplimiento de los contratos para ambos $^{32}$. Desde este punto de vista, la indemnización del interés positivo podría otorgar el incentivo correcto en la elección de cumplir o incumplir el contrato, sobre todo cuando una renegociación del contrato parece poco probable ${ }^{33}$.

(f) En relación directa al argumento anterior, se sostiene que la indemnización del interés positivo incentivaría el incumplimiento eficiente de los contratos $^{34}$. Según los seguidores de la teoría del incumpli-

28 Fried, Charles (1996). La obligación contractual. El contrato como promesa. Traducción de Ruiz-Tagle Vial, Pablo. Santiago: Editorial Jurídica de Chile, pp. 34-35.

29 Craswell, Richard (2000). "Against Fuller and Perdue". University of Chicago Law Journal, $\mathrm{N}^{\circ}$ 67, pp. 99-162, pp. 122-125.

30 Craswell, Richard (2006). "Expectation Damages and Contract Theory Revisited". Stanford Public Law Working Paper No. 925980. Stanford Law and Economics Olin Working Paper No. 325. Disponible en: http://ssrn.com/abstract=925980 [fecha de visita 13 de octubre de 2010] pp. 20-21.

31 Larenz, Karl (1958). Derecho de obligaciones. Traducción de Santos Briz, Jaime, Madrid: Editorial Revista de Derecho Privado, t. I, vol. 2, p. 392.

32 Kelly, Michael (1992). "The phantom reliance interest in contract damages". Wisconsin Law Review, 1992, pp. 1755-1846, p. 1787.

33 Craswell (2000) 109.

34 SLawson (1990) 226. El tema es más bien analizado por las doctrinas del análisis económico del derecho. Por ejemplo, Posner, Richard (2007). Economic Analysis of Law. $7^{a}$ ed., New York: Wolkers Kluwer, pp. 118 y ss.; Birmingham, Robert (1969-1970). "Breach of contract, damage measure, and economic efficiency", Rutgers Law Review, vol. 24, pp. 273 292, pp. 281-286; Friedmann, David (1989). "An economic analysis of alternative damage 
miento eficiente el remedio indemnizatorio es la medida perfecta de satisfacción del derecho y solo las las condenas por vía de interés positivo sirven a tal propósito ${ }^{35}$. El interés positivo viene a reemplazar la prestación debida, no dejando a ninguna de las partes en peor estado: al contratante lesionado, porque vería su prestación pagada, y al incumplidor, ya que se beneficiaría del incumplimiento eficiente, logrando una mejor forma de asignación de recursos ${ }^{36}$.

(g) En cuanto al interés del contratante inocente, no puede decirse que aquel tenía interés en que las cosas sucedieran como si el contrato no se hubiese celebrado, sino al contrario, al contratar lo que quiso el contratante diligente es que el contrato efectivamente se hubiese cumplido $^{37}$. Siguiendo esta cadena argumentativa, se ha señalado que cuando se indemnizan los perjuicios resultantes de la infracción del contrato basados en la pura confianza en que el contrato se celebrara (interés negativo), no habría diferencias entre otorgar perjuicios en sede contractual y en sede extracontractual ${ }^{38}$.

(h) En relación con el punto anterior, se contesta a la objeción que existiría una renuncia al interés negativo señalando que hay una diferencia entre la opción de cumplimiento, que es la ejecución en naturaleza de la obligación, y el interés positivo, que solo envuelve los beneficios que le hubiera reportado el cumplimiento íntegro y oportuno de la obligación ${ }^{39}$.

(i) Contestando la idea de que la indemnización del interés positivo es un problema de justicia distributiva, se sostiene que la indemnización del expectation interest, siendo una forma de reparación del dańo, es una cuestión de justicia correctiva que pertenece al derecho privado $^{40}$.

rules for breach of contract". Journal of Law \& Economics. $\mathrm{N}^{\circ} 32$, pp. 281-310, pp. $287 \mathrm{y}$ ss.; LeItzel, Jim, (1989). "Reliance and contract breach". Law and contemporary problems, vol. 52, 87-105, pp. 89 y ss.; SHAvell, Steven (1980). "Damage measures for breach of contract”. The Bell Journal of Economics, vol. $11 \mathrm{~N}^{\circ} 2$, pp. 466-490. En contra de la doctrina del incumplimiento eficiente puede verse Aтryah, P.S. (2001): "Excecutory Contracts, Expectation Damages, and the Economic Analysis of Law". En Atiyah, P.S.: Essays on contracts. New York: Oxford University Press, pp. 150-178; Friedmann, Daniel (1989). "The Efficient Breach Fallacy". The Journal of Legal Studies, vol. 18, pp. 1-24.

FRIEDMANN (1989) 1.

Posner (2007) 119-120.

IвÁÑEZ (2006) 337-340; véase los argumentos reproducidos por Genicon (2007) 746-749. Es precisamente uno de los argumentos que ocupa GiLMORE para sostener que la noción de contrato se encuentra muerta. Gilmore, Grant (1995) The death of contract. 2a ed. Columbus: The Ohio State University Press, pp. 5-112.

39 Véase los argumentos reproducidos por Genicon (2007) 748.

40 Craswell (2006) 23-24. Mismo argumento se encuentra en Weinrib, Ernest J. (2002).

"Corrective justice in a nutshell". University of Toronto Law Review, vol. 52, pp. 349-356, p. 353. 
Como puede apreciarse, existen fuertes argumentos que permiten sostener que la indemnización de daños consecuencial a la resolución del contrato puede medirse según el criterio del interés positivo. La pérdida de eficacia del contrato no obsta a que el acreedor pueda solicitar los perjuicios como si el contrato hubiese existido y se hubiere cumplido. Tal como hemos tenido oportunidad de estudiar, no hay problemas de lógica jurídica ni contradicciones en la defensa del interés positivo.

Pero que sea admisible a nivel lógico jurídico no quiere decir que haya sido aceptado por nuestra legislación positiva. Es necesario, por tanto, analizar si en el sistema de remedios al incumplimiento contractual previsto en el Código Civil chileno la indemnización de perjuicios en la resolución debe ser avaluada según el interés negativo o sobre el interés positivo.

\section{3) DEFENSA DEL INTERÉS POSITIVO COMO CRITERIO INDEMNIZATORIO EN LA RESOLUCIÓN POR INCUMPLIMIENTO}

Adelantamos desde ya nuestra posición. Nuestra tesis consiste en que el perjuicio resolutorio debe avaluarse según el criterio del interés positivo o de expectativa de cumplimiento.

A pesar de que no existe una regla explícita en el Código que permita sostener la resarcibilidad del interés positivo, se sostendrá que la acción de perjuicios contenida en la referida norma es una forma de protección del crédito que permite avaluar la indemnización según la expectativa de cumplimiento.

Esta acción de perjuicios es complementaria a las restituciones mutuas. De esta manera, el interés negativo del acreedor se ve remediado por los efectos extintivos/restitutorios de la resolución, y el interés positivo a través de la acción de perjuicios.

\section{(3.1.) LA INEXISTENCIA DE UNA REgLA EXPLÍCITA EN EL Código CIVIL QUE LIMITE LA INDEMNIZACIÓN RESOLUTORIA AL INTERÉS NEGATIVO}

El tenor literal de las normas del Código Civil chileno que regulan la indemnización de perjuicios en la resolución contractual no permite determinar cuál es el interés indemnizatorio protegido.

La regla de perjuicios del artículo 1489, debe construirse sobre la base de esta norma más las contenidas en el Título XII del Libro IV, "Del efecto de las obligaciones", particularmente las normas previstas en los artículos 1556 y 1558.

Por una parte, como ha señalado parte de la doctrina las nociones legales de daño emergente y lucro cesante, con fuente en el artículo 1556, 
son igualmente aplicables tanto a las hipótesis de indemnización de perjuicios por interés negativo y positivo ${ }^{41}$.

Y por otro lado, la norma del artículo 1558 sobre previsibilidad de los daños también puede interpretarse en un doble sentido, esto es, tanto a favor de la admisibilidad de los daños derivados del interés positivo como del interés negativo.

Se puede estimar que los daños, según la regla de previsibilidad, son aquellos que derivan de la inejecución del contrato mismo. Así, se podría argumentar que la ley protege la expectativa de cumplimiento porque los perjuicios que se valoran son aquellos que "fueron una consecuencia inmediata o directa de no haberse cumplido la obligación" (artículo 1558). Sin embargo, argumentando a favor del interés negativo, se podría decir que los daños como consecuencia directa e inmediata son aquellos que se producen en el patrimonio del deudor en la diferencia real producida por la no conclusión del contrato ${ }^{42}$.

Por ello, la regla de previsibilidad de los dańos contractuales del artículo 1558, tampoco nos ofrece una solución al problema planteado sobre el interés indemnizable.

Por lo dicho, para la determinación del interés indemnizable en el Código Civil, es necesario acudir a la función de la resolución contractual y concretamente a la de la indemnización de los perjuicios resolutorios.

41 Como lo hace ver Treitel, frecuente y equivocadamente se asimila daño emergente a dańo al interés negativo y lucro cesante a dańo al interés positivo. Treitel, G. H. (1988). Remedies for breach of contract. A comparative account. New York: Oxford University Press, pp. 84-85. Fuller / Perdue ya lo habían explicado. Fuller / Perdue (1936-1937) 55-56. Sobre la aplicación de las categorías de interés positivo y negativo a los criterios de daño emergente y lucro cesante, LAITHIER (2007) 167 y ss.

42 La regla de la previsibilidad de los daños se ve alterada si se aplica el criterio del daño al interés positivo o del daño al interés negativo. Fuller / Perdue ya habían identificado la problemática que envolvía la aplicación del criterio de previsibilidad a los daños por la expectativa, entendiendo que es mejor aplicarla a los reliance damages, ya que estimaban que las condenas por interés positivo eran demasiado onerosas (aun por la aplicación de la regla de precisibilidad) por un incumplimiento contractual: Fuller / Perdue (1936-1937) pp. 84-88. Un análisis exhasutivo de la regla de previsibilidad a los dańos que deriven del interés contractual positivo y negativo excede los márgenes del presente estudio, por lo que sería posible en el futuro una nueva investigación sobre el tema. 


\section{(3.2.) LA FUNCIÓN DE LA RESOLUCIÓN Y DE LA INDEMNIZACIÓN DE LOS PERJUICIOS RESOLUTORIOS}

\section{(3.2.1) Resolución e indemnización: entre protección del patrimonio y protección del crédito}

Ante el incumplimiento del deudor de una de sus obligaciones en un contrato bilateral, en principio, dos son los remedios que se activan frente a este: la pretensión de cumplimiento y la resolución del contrato.

En el caso de la pretensión de cumplimiento, tiene lugar precisamente el cumplimiento (in natura o por equivalencia) más la indemnización de perjuicios. Tratándose de la resolución por incumplimiento hay dos remedios que se acumulan: por una parte, tiene lugar la extinción de las obligaciones pendientes (artículo $1568 \mathrm{~N}^{\circ}$ 9), o bien, si el acreedor cumplió, las restituciones mutuas previstas en los artículos 1487 y 1488 del Código Civil ${ }^{43}$, y además procede la indemnización de perjuicios ("con indemnización de perjuicios").

Es claro que la pretensión de cumplimiento protege el interés positivo. En cambio, desde el punto de vista de la resolución, hay dos instituciones que se complementan para remediar la situación del incumplimiento contractual: el derecho extintivo o restitutorio (según el caso) y la acción indemnizatoria. Estos efectos de la resolución son propiamente los remedios a disposición del acreedor activados por la facultad resolutoria. Señalamos que propiamente son los remedios, porque con el solo acto de voluntad del acreedor en aras a extinguir la relación contractual a través de la resolución no basta para satisfacer el interés del acreedor. Por tanto, son sus efectos, extintivo/restitutorio e indemnizatorio, los medios a través de los cuales el acreedor verá remediada su situación de menoscabo.

Así, entonces, el remedio extintivo o restitutorio tiene por objeto colocar al acreedor en la posición que tendría dicho contratante como si no hubiese contratado, es decir, el remedio restitutorio protege el interés negativo, si bien el derecho restitutorio no tiene una función indemnizatoria $^{44}$.

43 Los autores nacionales están contestes en este efecto. Por todos, Abeliuk (2005) t.1, 461.

44 Se ha planteado la interrogante si las restituciones mutuas derivadas de la resolución son propiamente indemnizatorias. Pinna (2007) 55, opina que las restituciones mutuas en materia de resolución de contrato tienen, derechamente, la función de colocar a las partes en el mismo estado como si no se hubiese celebrado el contrato. Sin embargo, nos parece, siguiendo a Messineo, que la acción para la reclamación de la cosa por efecto restitutorio responde a que por la resolución el deudor pierde el título para detentar la cosa: Messineo, Francesco (1955). Manual de Derecho Civil y Comercial. Buenos Aires: Ediciones Jurídicas Europa-América, t. IV, p. 37. En sentido similar, se pronuncia Díez-PICAzo (2008) t. II, 872. Por tanto, a nuestro entender, las restituciones mutuas consecuenciales a la resolución no cumplen una función propiamente indemnizatoria. 
La cuestión a resolver es si la indemnización que acompaña al efecto extintivo/restitutorio debe igualmente cubrir el interés negativo; o bien, al contrario, debe proteger la expectativa de cumplimiento del contrato.

Si se sigue la primera de las opciones enunciadas, esto es, que la indemnización de los perjuicios resolutorios se fundarían en el criterio del interés negativo, la indemnización cumpliría una función de protección del patrimonio del acreedor al intentar colocarlo a través de ella como si no se hubiese celebrado el contrato, de manera bastante similar a como operaría una acción por responsabilidad extracontractual. Bajo este prisma, la indemnización de los perjuicios tendría por objeto complementar aquello que no ha sido remediado por el efecto extintivo o restitutorio de la resolución. La protección del patrimonio del deudor, como posible función de la resolución y de la acción de perjuicios, se fundaría no en el incumplimiento del contrato, sino en la extinción del contrato como hecho generador de responsabilidad.

En cambio, si se sugiere la segunda de las opciones, esto es, que la indemnización de los perjuicios cubre el interés positivo, la indemnización de los perjuicios cumpliría una función de protección del crédito del acreedor, que intenta colocarlo en aquella posición como si el contrato hubiese sido cumplido. Bajo esta óptica, los daños indemnizables en este supuesto, derivan del incumplimiento del contrato que es el hecho generador de la responsabilidad contractual. La reparación del interés positivo, como criterio de avaluación de los dańos, sería complementaria a los efectos extintivo/restitutorio de la resolución del contrato.

Frente a esto, se puede invocar el principio de fuerza obligatoria del contrato, que solo sería compatible con la acción de cumplimiento y con el interés positivo que ella implica.

\section{(3.2.2) Protección del crédito y principio de fuerza obligatoria del contrato}

Tradicionalmente, se ha sostenido que la forma de protección del crédito tiene lugar únicamente por el ejercicio de la pretensión de cumplimiento. La razón residiría en el principio de la fuerza obligatoria de los contratos que impone el cumplimiento de los contratos recogido en artículo 1545 del Código Civil.

Por lo tanto, cualquier voluntad del acreedor que no pretendiera el cumplimiento forzado del contrato no podría calificarse como forma de protección del crédito $^{45}$. Más aún: la resolución del contrato por incum-

45 El origen del argumento parece encontrarse en la interpretación del artículo 1134 del Code por los primeros comentaristas del mismo, como nos hace ver Laithier, Yves-Marie (2005). "Comparative Reflections on the French Law of Remedies for Breach of Contract". En Cohen, Nili y Mckendrick, Ewan (eds.): Comparative remedies for Breach of Contract. Portland: 
plimiento sería una excepción al principio de la fuerza obligatoria del contrato ya que, precisamente por el evento de la resolución, se extinguiría el contrato y se desestimaría la finalidad de su ejecución ${ }^{46}$.

La indemnización de los perjuicios constituiría un remedio secundario frente a la pretensión de cumplimiento, ya que no perseguiría propiamente el cumplimiento in natura de la obligación, garantizado por el principio de la fuerza obligatoria del contrato ${ }^{47}$. Sin embargo, en nuestra opinión, esta concepción que opone el principio de fuerza obligatoria de los contratos a los remedios contractuales diversos de la pura pretensión de cumplimiento, confunde la regla de cumplimiento con el remedio ${ }^{48}$. La oposición entre principio de fuerza obligatoria del contrato y resolución no es correcta puesto que el artículo 1545 no determina cuáles son los remedios de que goza el acreedor afectado ${ }^{49}$ y lo único que establece es que el contrato es legalmente obligatorio para las partes. La norma, por lo tanto, solo establece que los contratos deben ser cumplidos, pero no determina qué medios tiene el acreedor para la satisfacción del crédito que ha adquirido en virtud del contrato.

De esta suerte, frente al incumplimiento del deudor, el artículo 1545 debe complementarse con todas aquellas normas que regulan los efectos del incumplimiento y, en el caso de los contratos bilaterales, particularmente con el artículo 1489. Por tanto, la protección de la fuerza obligatoria del contrato no se encuentra en la mera consagración normativa del principio, sino en los remedios de que goza el acreedor para obtener la completa satisfacción de su interés. En el caso de un contrato bilateral, la pretensión de cumplimiento forzado o la resolución, y en ambos casos con indemnización de perjuicios. No puede señalarse que existe una opo-

Hart Publishing, pp. 103-122, pp. 108-112; con mayor profundidad, Laithier (2007) 39 y ss. En Chile, Claro parece de la misma opinión: "De este modo, pues, que al decir que el art. 1545 que el contrato es una ley para los contratantes, se dirige al mismo tiempo al juez; desde que, suscitándose cualquiera controversia entre los contratantes referente a la ejecución del contrato, es el juez llamado a procurar como autoridad pública el cumplimiento de las obligaciones tales como en el contrato fueron establecidas". Claro Solar, Luis (1979). Explicaciones de derecho civil chileno y comparado. Edición facsimilar de la $2^{\text {a }}$ ed. Santiago: Editorial Jurídica de Chile, t. 10, p. 471.

46 Laithier (2005) 117.

$47 \quad$ Así lo exponen, entre otros, el mismo Claro (1979) 723; Gatica Pacheco, Sergio (1959). Aspectos de la indemnización de perjuicios por incumplimiento de contrato. Santiago: Editorial Jurídica de Chile, pp. 20-21; AвELIuk (2005) t. II, 727.

48 Sobre el particular, seguimos a Laithier (2005) 112.

49 Pizarro señala que el artículo 1545 se limita a declarar la obligatoriedad del contrato sin pronunciarse sobre si el fundamento de esta es la voluntad de las partes: Pizarro Wilson, Carlos (2004). "Notas críticas sobre el fundamento de la fuerza obligatoria del contrato. Fuentes e interpretación del artículo 1545 del Código Civil Chileno". Revista Chilena de Derecho, vol. $32 \mathrm{~N}^{\circ} 2$, pp. 225-237, pp. 236-237. Siguiendo este planteamiento, puede decirse que el artículo 1545 se limita a declarar la obligatoriedad del mismo contrato y no determina los remedios contractuales que operan frente a la inejecución. 
sición entre el principio y el remedio ${ }^{50}$; al contrario, ellos se complementan ya que determinan en qué medida la obligatoriedad contractual es tutelada por el ordenamiento jurídico: a elección del acreedor, o el cumplimiento o la resolución del contrato ${ }^{51}$.

Pues bien, si no existe contradicción entre la fuerza obligatoria del contrato y la resolución y sus efectos, que es uno de los remedios alternativos frente al incumplimiento del contrato, puede concluirse que ella cumple también (al igual que la pretensión de cumplimiento) una función de protección del crédito incumplido.

Pero si esto es así, hay que convenir en que el solo efecto liberatorio/ restitutorio de la resolución no podría cumplir por sí solo esta función. La debida complementación del principio de la fuerza obligatoria con el remedio resolutorio solo puede darse por el establecimiento de carácter legal de la indemnización de los perjuicios, que tendrá por objeto precisamente el resarcimiento del daño sufrido por el acreedor por el incumplimiento del contrato. Si bien el acreedor no obtiene por la resolución el cumplimiento in natura, la ley concede una acción que tiene por objeto colocarlo en una posición similar a la que hubiera tenido si el contrato hubiese sido cumplido.

Por lo anterior, no puede considerarse el remedio indemnizatorio como uno de carácter secundario respecto de la pretensión de cumplimiento o de la resolución. Para remediar la situación contractual del acreedor, la ley le ha concedido una acción de perjuicios complementaria a la acción resolutoria. La indemnización resolutoria puede considerarse como una forma de protección del crédito incumplido, al igual que la pretensión de cumplimiento.

Si la acción de perjuicios en caso de resolución es un remedio que protege el crédito por el incumplimiento contractual, entonces hay que entender que los dańos que el juez debe tener en consideración para la avaluación de la indemnización deben encontrarse en la esfera del interés positivo.

50 En el caso del Código Civil chileno la cuestión es más clara que en el derecho francés. En el Code la resolución y sus consecuencias operan solo en caso de imposibilidad de cumplimiento del contrato; en cambio, el Código chileno establece una opción entre reclamar el cumplimiento o la resolución del contrato. Seguimos a Laithier (2005) 117, sobre la base de los artículos 1134 y 1184 del Code. El mismo argumento puede encontrarse en PaLazón (2009) 809.

51 Genicon es crítico frente a la posición de Laithier, por estar basada en una concepción anglosajona. Señala que la situación en Francia es distinta ya que existe un fuerte arraigamiento de una obligación moral de cumplimiento de los contratos, lo que implicaría la primacía del cumplimiento de los contratos frente a otros remedios. De esta suerte, estima que la redacción de la norma se refiere a una política legislativa de preferencia a la ejecución forzada: Genicon (2007) 261 y ss. En Chile, a diferencia de Francia, no existe una preeminencia legal de la pretensión de cumplimiento a la facultad resolutoria por la redacción de nuestro artículo 1489, que varió del artículo 1184 del Code. 


\section{(3.2.3) El criterio del interés positivo y su complementación con los efectos extintivo y restitutorio de la resolución}

Como ya hemos tenido oportunidad de señalar, el interés negativo o de confianza permite establecer un marco de protección de los intereses del acreedor, que se basa en el amparo de la integridad patrimonial del mismo. El interés negativo tiene por objeto impedir que el patrimonio del acreedor se vea disminuido por el incumplimiento ${ }^{52}$.

Sin embargo, el establecimiento legal de la indemnización de perjuicios en caso de la resolución de contratos, como argumentamos unas líneas atrás, solo tiene sentido como instrumento de protección del crédito incumplido y no de protección del patrimonio del acreedor. Lo que se intenta a través de ella es que el mismo crédito sea satisfecho, permitiendo al acreedor ser colocado en una posición similar a la que hubiera tenido si el contrato hubiese sido cumplido. El interés contractual positivo es la fórmula que permite al acreedor la protección del interés en el crédito.

Esto también se armoniza perfectamente con la acumulación de remedios resolutorios previstos en el artículo 1489. En la resolución por inejecución, el efecto liberatorio/restitutorio tiene por objeto la protección del patrimonio (es una regla de propiedad), mientras la indemnización de perjuicios tiene por fin la protección del crédito (es una regla de responsabilidad $)^{53}$.

Si ya las restituciones mutuas protegen el patrimonio del deudor evitando su disminución por el efecto del incumplimiento, la indemnización de perjuicios no puede intentar cubrir lo mismo. Se estaría protegiendo dos veces el mismo daño a través de remedios distintos.

La indemnización de los perjuicios consecuenciales a la resolución es una verdadera regla de responsabilidad contractual. Esta regla permite al juez la valoración de lo que la infracción contractual le ha causado al acreedor. Como ya ha operado el efecto extintivo/restitututorio, no podría la indemnización intentar volver a cubrir esta circunstancia. Por el

\section{Craswell (2000) 125-127.}

Se toma como base la aplicación de la distinción que hace KRONMAN entre reglas de propiedad y responsabilidad. KRONMAn estima que una regla de propiedad en materia contractual es aquella que protege el derecho a la prestación. Una regla de responsabilidad es aquella que permite al deudor incumplir su contrato, compensando a la otra parte los perjuicios resultantes de la infracción al mismo: Kronman, Anthony (1978). "Specific Performance". University of Chicago Law Review, vol. 45, pp. 351-382, pp. 352 y ss. Así, en materia de resolución la regla de propiedad está determinada por el derecho restitutorio que es, precisamente, la prestación pagada que se intenta recuperar por la acción restitutoria; y la regla de responsabilidad que es la indemnización de los perjuicios consistente en la valoración del incumplimiento contractual. La distinción originaria entre normas de propiedad y de responsabilidad tiene su fuente en Calabresi, Guido / Melamed, Douglas (1972). "Property Rules, Liability Rules and inalienabilty: one view of the cathedral". Harvard Law Review, vol. 85 , pp. 1089-1128. 
contrario, deberá abarcar la situación patrimonial en la que se encontraría el acreedor si el contrato le hubiese sido cumplido, esto es, el interés positivo.

Se permite al acreedor ser compensado en el crédito incumplido a pesar de haber optado por la acción resolutoria. Haciendo compatible la indemnización del interés positivo con los otros efectos resolutorios, se asegura al acreedor que frente al incumplimiento del deudor su expectativa de cumplimiento del contrato será protegida, ya sea que ejerza la pretensión de cumplimiento, ya sea que prefiera la acción resolutoria. Por el otro lado, el deudor sabrá que estará sujeto a responder en todo caso por los riesgos de la expectativa de cumplimiento frustrada.

\section{4) Dificultades QUE PlaNTEA la INDEMNIZACIÓN DE PERJUI- CIOS FUNDADA EN EL INTERÉS POSITIVO}

En el presente capítulo se contestarán ciertas objeciones que pueden plantearse a nuestra teoría. En primer lugar, se tratará sobre el principal argumento que se ha sostenido para fundar el interés negativo, cual es la retroactividad de la resolución del contrato. Esperamos demostrar que, para efectos de la indemnización de los perjuicios resolutorios, la resolución no opera retroactivamente.

En segundo lugar se tratará sobre el argumento que sostiene que la resolución del contrato implica una renuncia al interés positivo. Se sostendrá, coincidentemente con la función de protección del crédito, que por la acción para reclamar los perjuicios resolutorios no se configura tal renuncia.

El tercer apartado está dedicado a tratar las diferencias entre la acción de perjuicios acumulable a la pretensión de cumplimiento y la acción de los perjuicios consecuenciales a la resolución. Se ha señalado que frente a una indemnización del interés positivo en caso de resolución, no existirían diferencias entre la ella y la pretensión de cumplimiento. Nuestra opinión es que las indemnizaciones son distintas. Y aun en el caso en que el quantum de ellas pueda coincidir, es distinta la posición en que se encontrará el acreedor frente a la pretensión de cumplimiento o de la resolución con una indemnización fundada en el interés positivo.

\section{(4.1.) EL PRETENDIDO EFECTO RETROACTIVO DE LA CONDICIÓN}

En la doctrina comparada se suele discutir si el efecto retroactivo de la condición alcanza a la indemnización de perjuicios. Si la plenitud de los efectos de la condición resolutoria cumplida fueren retroactivos, afectando asimismo la indemnización de perjuicios, el interés indemnizable sería necesariamente el negativo. 
La cuestión podría presentarse también en Chile, porque siguiendo al Code, la resolución por inejecución fue tratada legalmente como una verdadera condición más que como un efecto del incumplimiento contractual $^{54}$. Pero, a diferencia del Código Civil francés, la ley no ha establecido ninguna norma que prescriba la retroactividad del cumplimiento de las condiciones ${ }^{55}$, y en la doctrina nacional, el punto es discutido ${ }^{56}$.

Si se pretende que la resolución opera con plenos efectos retroactivos, la situación parece asemejarse a la que se presenta en la responsabilidad por contrato nulo y en la responsabilidad in contrahendo puesto que no existiría contrato, y la avaluación de los daños quedaría regida por el interés negativo ${ }^{57}$. Por el contrario, si se estima que la resolución no opera con efectos retroactivos no puede impedirse la indemnización del interés positivo.

Para la indemnización de perjuicios en materia de resolución por inejecución, en Chile, creemos que la resolución no opera retroactivamente, por las siguientes razones:

54 Como la doctrina nacional ya lo ha venido postulando: por ejemplo, Fueyo Laneri, Fernando (2004). Cumplimiento e incumplimiento de las obligaciones. $3^{\text {a }}$ ed. Santiago: Editorial Jurídica de Chile, pp. 305-306; Peñailillo Arévalo, Daniel (2003). Obligaciones. Santiago: Editorial Jurídica de Chile, pp. 395-399.

55 Aunque en la resolución por inejecución del Code no hay norma precisa que determine los efectos retroactivos, sí se estima aplicable el artículo 1183 inciso $1^{\circ}$ al efecto: "La condition résolutoire est celle qui, lorsqu'elle s'accomplit, opère la révocation de l'obligation, et qui remet les choses au même état que si l'obligation n'avait pas existé". [La cursiva es nuestra]. La solución es idéntica en Francia y Bélgica. Esta última reproduce el mismo artículo. DeLvaux, Paul-Henry (2001): "Les effets en droit belge de la résolution des contrats pour inexécution”. En Fontaine, Marcel / Viney, Geneviève (eds.): Les sanctions de l'inexécutions des obligations contractuelles. Paris: L.G.D.J., pp. 669-697, p. 672.

56 Se discute si la regla general es que la condición opere con o sin efecto retroactivo. En busca de una regla general, la doctrina nacional no es uniforme. Ramos Pazos tiende a aceptar que el principio general de la legislación es la retroactividad y por tanto a los casos especialmente no regulados por ley debe otorgárseles efecto retroactivo. Ramos Pazos, René (2008). De las obligaciones. $3^{a}$ ed. Santiago: LegalPublishing, pp. 149-150. En el mismo sentido, Cousiño Mac-Iver, Luis (1926). De la condición Suspensiva (memoria de prueba). Santiago: Universidad de Chile, pp. 96-97. Aвeliuk es de la opinión que la ley no establece una regla general y hay que analizar caso a caso reconociéndole al intérprete la facultad de interpretación más próxima a las soluciones dadas por el Código a situaciones similares. Abeliuk Manasevich, René (2005). Las obligaciones. 4a ed. Santiago: Editorial Jurídica de Chile, t.1, p. 451. En el mismo sentido opina Somarriva como aparece en Alessandri Rodríguez, Arturo / Somarriva Undurraga, Manuel / Vodanovic Haklicka, Antonio (2001). Tratado de las obligaciones. Santiago: Editorial Jurídica de Chile, 1.1, p. 261, nota 30; Peñailillo (2003) 380.

57 Por la mayoría que sostiene el interés negativo en la responsabilidad precontractual, BARrientos (2008), pp. 64-72. No obstante, en contra se pronuncia Segura Riveiro, Francisco (2007). "El interés indemnizable en las hipótesis de responsabilidad precontractual". En Corral Talciani, Hernán / Rodríguez Pinto, María Sara (coords.): Estudios de Derecho Civil II. Santiago: LexisNexis, pp. 345-362, pp. 357-362. Sobre la responsabilidad por contrato nulo en que se aplica la teoría de la responsabilidad in contrahendo, Alonso TRAviesa, María Teresa (2006). El problema de la concurrencia de responsabilidades. Santiago: LexisNexis, pp. 185-191. 
(1a) Desde el punto de vista histórico, resulta dudoso que el origen de la acción de perjuicios en caso de resolución de contratos contemplara una indemnización de perjuicios fundada en el interés negativo cuando operara la resolución. Domat, a quien se atribuye la primera fórmula moderna de la resolución por incumplimiento ${ }^{58}$, fundó la indemnización de perjuicios en el id quod interest del acreedor y ello supone la no retroactividad del contrato resuelto ${ }^{59}$.

(2a) Si el codificador chileno hubiese querido que la resolución operara con plenos efectos retroactivos, incluso para la indemnización de daños contractuales, lo habría prescrito expresamente, cosa que no hizo apartándose manifiestamente en este punto del Código Civil francés ${ }^{60}$.

(3a) A nuestro entender, el Código no adoptó un efecto retroactivo para las demás partidas restitutorias (frutos, mejoras y deterioros), lo que nos hace pensar que el codificador estableció un sistema no retroactivo. En efecto, los frutos no se restituyen (artículo 1488) ${ }^{61}$; tampoco las mejoras y los deterioros (artículo 1486 inciso $2^{\circ}$ ). Ahora, si la cosa perece (artículo 1486 inciso $1^{\circ}$ ) o se deteriora por culpa del deudor (artículo 1486 inciso $2^{\circ}$ ), se debe el precio de la cosa, lo que nos lleva a concluir que este subroga a la obligación restitutoria ${ }^{62}$.

(4a) Legalmente la causa del daño encuentra su fuente en el incumplimiento del contrato y no en su resolución. El incumplimiento se refiere a la reparación de los dańos causados por este, habiendo existido obviamente contrato, y no a los perjuicios que deriven

58 Dell'Aquila, Enrico (1981). La resolución del contrato bilateral por incumplimiento. Salamanca: Ediciones Universidad de Salamanca, pp. 84 y ss.

59 Véase las referencia "L.6, c. de her act." en Domat, Jean (1777). Les lois civiles dans leur ordre natural. Paris: Nyon, L.I, tit. I, sec. 3 n. 4, que sugiere el texto ubicado en C.54.6; y la referencia "L.1. ff. de act. empt \& vend. L. 4. c. cod" en Domat (1777) L.I, tit. I, sec. 6, n.11, que aludiría a los textos ubicados en D. 19.1 y C. 4.49.2.

60 La retroactividad prescrita en el Code y sus supuestos fundamentos (ficción y voluntad presunta de las partes), ha sido criticada por la misma doctrina francesa: Leloutre, Amdée (1907). "Estudio sobre la retroactividad de la condición". Revista de Derecho y Jurisprudencia, t. 5, $1^{a}$ parte, pp. 161-175, pp. 174-175; Serinet, Yves-Marie (2007). "L'effet rétroactif de la résolution pour inexécution en droit français". En Fontaine, Marcel / Viney, Geneviève. Les sanctions de l'inexécutions des obligations contractuelles, Paris: L.G.D.J., pp. 589668, pp. 643 y ss.

61 Con la excepción de la resolución de la compraventa por no pago del precio en virtud del artículo 1875.

62 Algunos autores han planteado que los artículos 1490 y 1491 también contemplarían un principio de efectos no retroactivos de la resolución (véase a los autores citados en n. 55), cuando el tercero adquirente se encuentra de buena fe. Sin embargo, a nuestro entender estas normas se justifican por una razón diversa: sería de justicia que el tercero de buena fe no asumiera los riesgos del incumplimiento de un contrato previo. Por tanto, estas normas, a nuestro entender, no se pueden justificar desde el punto de vista de los alcances retroactivos (o no) de la resolución contractual. 
de su resolución. La letra de la ley así parece sugerirlo. El artículo 1489 establece la acción de perjuicios por el incumplimiento, no por la resolución del contrato. En efecto, la norma dispone la activación de los remedios por no cumplirse lo pactado ("pero en tal caso"), no por las consecuencias que la resolución retroactiva hubiere acarreado.

(5) En otros supuestos de resolución por inejecución, al parecer, el Código también mira la indemnización de perjuicios como resarcimiento por evento de un incumplimiento del contrato y no como un efecto de la resolución. Esta sería la situación de los artículos 1853 , en caso de evicción parcial ("y todo otro perjuicio que de la evicción resultare al comprador"63) y 1855 (interpretándolo a contrario sensu, esto es, si la sentencia da lugar a la evicción, el vendedor sí es obligado a indemnizar los perjuicios producto de la misma); artículo 1865 en materia de vicios redhibitorios, cuando hay culpa en la omisión de la información de los vicios ${ }^{64}$; y en el artículo 1933 , a propósito del arrendamiento también por vicios redhibitorios, por las mismas razones.

(6a) En un sistema puramente retroactivo la acción de perjuicios no debería tener lugar. Bastaría con haber establecido la retroactividad de la condición para determinar la operatividad de las restituciones mutuas y dejar entregada la indemnización de los dańos a las reglas generales de la responsabilidad extracontractual. Sin embargo, el Código, por el incumplimiento de un contrato, estableció legalmente una indemnización complementaria a la resolución del contrato.

Fundada la irretroactividad de la resolución respecto de la indemnización de los perjuicios resolutorios, creemos que el sistema del Código Civil se asemeja bastante a los sistemas "modernos" en materia de efectos de la resolución. Estos sistemas hacen compatibles el efecto restitutorio con el indemnizatorio, ya que entienden la resolución como un modo de liquidar las relaciones entre acreedor y deudor, que en definitiva se ve de-

63 [La cursiva es nuestra]. No de la "rescisión" (léase resolución) a la que alude en la parte primera del mismo artículo. Lo que produce el perjuicio es la evicción que es la concretización del incumplimiento de entregar de la cosa.

64 La doctrina mayoritaria en Chile estima que la acción redhibitoria es propiamente resolutoria, opinión que compartimos. Sin embargo, hay autores que opinan que la acción es rescisoria. Por la minoría, Baraona González, Jorge (2008). "La acción redhibitoria como acción de nulidad”. En Guzmán Brito, Alejandro (ed.): Estudios de Derecho Civil III. Santiago: LegalPublishing, pp. 659-669. GuzMÁn, que también es de la misma opinión minoritaria, propugna una independencia de la acción indemnizatoria en caso de redhibición. GuzMán Brito, Alejandro (2007). "Sobre la relación entre las acciones de saneamiento de los vicios redhibitorios y las acciones comunes de indemnización, con especial referencia a su prescripción”. Revista Chilena de Derecho Privado, N 9, pp. 95-120, pp. 99-101. 
terminado por la indemnización de los perjuicios resultantes de la infracción del contrato, avaluada bajo el prisma del interés positivo ${ }^{65}$.

\section{(4.2.) LA SUPUESTA RENUNCIA AL INTERÉS POSITIVO}

A pesar de que la resolución pueda operar sin efecto retroactivo respecto de la indemnización de perjuicios, algunos autores han sostenido que la opción resolutoria constituye una renuncia a la expectativa de cumplimiento.

Cabe recordar que si se solicita la resolución del contrato, el contratante que la pide no tiene intención de cumplir por su parte lo pactado (de hecho, su obligación se extinguirá), y si cumplió, obtendrá restitución (que protege el interés negativo). Por tanto, para algunos autores, no tendría razón de ser que la ley estableciera la indemnización de perjuicios que cubra el interés positivo para un caso de resolución de contrato, dado que el contratante diligente obtendrá restitución (o liberación en el cumplimiento). Por ello, se ha sostenido que la elección entre el cumplimiento y la resolución del contrato, en definitiva, es entre el interés positivo y negativo ${ }^{66}$, y si se opta por el negativo (la resolución) se entenderá renunciado el positivo.

El problema que plantea esta tesis es que sugiere la desaparición retroactiva del contrato ${ }^{67}$. Los dos argumentos que sostienen la resarcibilidad del interés negativo: retroactividad y renuncia, parecen estar atados. Por eso los argumentos ya ofrecidos en contra de la retroactividad, debieran servir para descartar la supuesta renuncia.

Además, creemos que la teoría es errónea porque habrá casos en los que no es posible sostener que el acreedor renunció al interés positivo al

65 Esta es la solución que adoptan los Principios del Derecho Europeo de los Contratos (PECL). El comentario B al artículo 9:305, que regula los efectos de la resolución del contrato, establece la inconveniencia de la retroactividad del contrato por efecto de la resolución. La razón comentada se debe a que el acreedor perdería la posibilidad de demandar perjuicios por la expectativa (el artículo 8:102 señala que por la resolución no se pierde el derecho a reclamar por los perjuicios) y la aplicación de otras cláusulas que se podrían aplicar a pesar de la resolución (por ejemplo, cláusula penal). Lando, Ole / Beale, Hugh (2000). Principles of European Contract Law. Cambridge: Kluwer Law International, p. 420. La reforma del BGB de 2002 siguió a los PECL en el particular, sin norma expresa aunque se desprende de su regulación, en especial del $\$ 346(4)$ que no priva al contratante inocente del derecho de reparación por el evento de la resolución. Markesinis, Basil / Unberath, Hannes / Johnston, Angus, (2006). The german law of contract. Portland: Hart Publishing, 2006, pp. 432-434; Zimmermann, Reinhard (2005). The new German law of obligations. New York: Oxford University Press, p. 73. Los Principios UNIDROIT sobre los Contratos Comerciales Internacionales (2004) adoptan un criterio similar en su artículo 7.3.5(2). En el Código holandés y en el Marco Común de Referencia se adopta la misma solución: PaLAzón (2009) 810-812.

66 Laithier (2007) 210.

67 Laithier (2007) 209 y ss. 
no ejercer la acción de cumplimiento, porque no tenía posibilidad de hacerlo. Hay situaciones en que, a pesar del incumplimiento del deudor, no puede el acreedor demandar la expectativa de cumplimiento del contrato (in natura o por equivalencia). Así, en las obligaciones de dar cosas específicas en las que el cumplimiento por equivalencia se puede confundir con la restitución ${ }^{68}$; y en aquellas situaciones en que la obligación de hacer no puede cumplirse forzosamente ${ }^{69}$.

En estos casos, la opción resolutoria se manifiesta como el remedio más adecuado para el acreedor sin que pueda suponerse voluntad de renunciar a la expectativa de cumplimiento. Si se consintiera en esto se dejaría al arbitrio del deudor el reparar o no el interés positivo. Esto es contrario a lo que la doctrina actual propugna: los remedios se encuentran en manos del acreedor, y no a discreción del contratante incumplidor ${ }^{70}$. Estos casos nos grafican que en ciertos supuestos el remedio se puede encontrar en manos del deudor, quien por su incumplimiento determinaría por un acto de su voluntad el interés indemnizable.

A nuestro entender, la actuación del deudor no debiera limitar la opción del acreedor en la expectativa de contrato, porque ello sería entregar la suerte del contrato y de los remedios al contratante incumplidor.

68 Imagínese que el vendedor no entrega la cosa específica, la que no es posible cumplir en naturaleza. Si no existe variación monetaria de la prestación, el valor de prestación (cumplimiento por equivalencia) es equivalente a lo que el comprador pagó por ella (si efectivamente pagó). Por tanto, en estos supuestos, en principio, la valoración monetaria del valor de prestación equivale a lo que el acreedor obtendría por medio de la restitución en caso de resolución del contrato.

69 Piénsese, por ejemplo, en un contrato de promesa de compraventa de un inmueble (que contiene una obligación de hacer, que es la de celebrar el contrato definitivo), en el que el promitente vendedor lo enajena a un tercero. El cumplimiento se hace imposible (en naturaleza o por equivalencia), y solo quedaría la opción resolutoria para obtener la restitución de lo que pagó (por ejemplo si había adelantado parte del precio, más los perjuicios que hubiere sufrido por el incumplimiento). Véase para un conjunto de casos comparados en que la prestación torna en imposible de ser cumplida forzosamente, Pantaleón (1989) 1143 1164.

70 En este sentido, Barros Bourie, Enrique (2008): "Finalidad y alcance de las acciones y los remedios contractuales”. En Guzmán Brito, Alejandro (ed.): Estudios de Derecho Civil III. Santiago: LegalPublishing, pp. 403- 428, pp. 406 y ss.; Pizarro Wilson, Carlos (2008). "Hacia un sistema de remedios al incumplimiento contractual". En Guzmán Brito, Alejandro (ed.): Estudios de Derecho Civil III. Santiago: Legal Publishing, pp. 398.400; VIDaL Olivares, Álvaro (2007): "El incumplimiento de obligaciones con objeto fungible y los remedios del acreedor afectado". En Guzmán Brito, Alejandro: El Código Civil de Chile (1855-2005), Santiago: LexisNexis, pp. 495-550, pp. 522 y ss. 


\section{(4.3.) LA DIFERENCIACIÓN ENTRE LAS INDEMNIZACIONES DERIVADAS DE LA PRETENSIÓN DE CUMPLIMIENTO Y LA RESOLUCIÓN POR INCUMPLIMIENTO}

\section{(4.3.1.) Diferencia en el contenido de los perjuicios}

Un tercer problema que puede plantear la tesis de la resarcibilidad del interés positivo es la confusión que puede producirse entre la indemnización en caso de cumplimiento y la indemnización de los perjuicios derivados de la resolución.

Se podría sostener que si tanto la pretensión de cumplimiento como la acción de perjuicios resolutorios se fundan en el interés positivo, las indemnizaciones en ambos supuestos serían idénticas o bien monetariamente equivalentes, por lo que no se daría una diferencia relevante para el acreedor entre demandar el cumplimiento o demandar la resolución. La alternativa del art. 1489 sería falsa.

Lo anterior sería correcto si el contenido de las indemnizaciones fuera el mismo. Pero sostener que la indemnización resolutoria protege el interés positivo, no conduce a afirmar que tiene el mismo contenido que los perjuicios que pueden reclamarse en caso de cumplimiento forzado.

Existe una importante diferencia de contenido: la indemnización de los perjuicios derivados de la pretensión de cumplimiento son moratorios; en cambio, en la resolución son compensatorios.

Cuando se solicita el cumplimiento del contrato, el acreedor busca la satisfacción, ya en naturaleza, ya por equivalencia de la prestación. Como ya lo ha señalado la doctrina, no es posible acumular el cumplimiento en naturaleza al cumplimiento "por equivalencia" (valor de prestación) ${ }^{71}$, y por ello, si el acreedor opta por el cumplimiento, solo podría solicitar los dańos moratorios y no los compensatorios ${ }^{72}$.

Por el contrario, en la resolución por incumplimiento, la indemnización de perjuicios debería tener por objeto la compensación al acreedor de los daños que derivan del incumplimiento contractual. Estos daños

71 VIAL del Río, Víctor (2007). Manual de las obligaciones en el código civil chileno. $2^{\text {a }}$ ed. Santiago: Editorial Biblioteca Americana, p. 239, es de la misma opinión por consideraciones diferentes. También, Pinna (2007) 206-207.

72 Si bien es posible concebir ciertas partidas "indemnizatorias" complementarias al cumplimiento de la obligación, creemos que ellas son más propias de la pretensión de cumplimiento, no de los daños compensatorios. En este caso no es que la indemnización cubra el interés positivo, sino que el interés en la expectativa se encuentra en la elección de la pretensión de cumplimiento. Como sería, por ejemplo, el caso de la posibilidad del reembolso de los costos de reparación de la cosa defectuosa. Vidal Olivares (2007), 529 y ss.; Morales Moreno, Antonio Manuel (2006). "El derecho a la reparación o sustitución de la cosa no conforme y la naturaleza de la obligación del vendedor". En Morales Moreno, Antonio Manuel: La modernización del derecho de obligaciones, Madrid: Aranzadi, pp. 195 y ss. 
compensatorios consisten, a nuestro entender, en el id quod interest del acreedor, desligados del valor de prestación o aestimatio rei ${ }^{73}$. Si por el evento de la resolución puede el acreedor de la obligación incumplida obtener una indemnización de perjuicios, en los que es verdaderamente perjuicios, deben estos desligarse del valor de prestación que ha sido subrogado por la consecuente obligación restitutoria. Por tanto, deben ser considerados como perjuicios para los efectos del artículo 1489 en caso de resolución contractual, los consecuenciales al incumplimiento, es decir, lo que le hubiese significado al acreedor el incumplimiento íntegro y oportuno de la obligación, esto es, su id quod interest.

A pesar de la diferenciación entre las indemnizaciones, la primera de carácter moratorio, la segunda de carácter compensatorio, trataremos de diferenciar la apreciación del daño en ambas hipótesis, distinguiendo si coinciden o no monetariamente.

\section{(4.3.2.) Casos en que la indemnización de cumplimiento no es equi- valente a la indemnización resolutoria}

Para comprobar la diferencia nos valdremos de ciertos casos jurisprudenciales en que se demandó una indemnización fundada en el interés negativo. Para los efectos que nos proponemos demostrar se señalará la diferencia existente entre el daño al interés negativo reclamado, la indemnización complementaria a la pretensión de cumplimiento y la indemnización por los perjucios resolutorios fundada en el interés positivo.

Veremos que el quantum de la indemnización variaría según si se trata de la indemnización moratoria (en caso de cumplimiento) o compensatoria (en caso de resolución). Razonaremos siempre en el entendido que se acojan todas las acciones.

73 En doctrina nacional se ha planteado la duda de si el concepto general de indemnización de perjuicios abarca únicamente el id quod interest, es decir, los daños consecuenciales; o bien, abarca también el valor de prestación o aestimatio rei como sustituto dinerario de la prestación imposible. Así, Baraona González, Jorge (1997). "Responsabilidad contractual y factores imputación de dańos: apuntes para una relectura en clave objetiva”. Revista Chilena de Derecho, vol. $24 \mathrm{~N}^{\circ}$ 1, Santiago, pp. 151-177, pp. 156-162; Bustamante Salazar, Luis, (2005). "Autonomía del equivalente pecuniario o su integración dentro de la indemnización de dańos y perjuicios". En Varas Braun, Juan Andrés / Turner Saelzer, Susan (coords.): Estudios de Derecho Civil. Santiago: LexisNexis, pp. 105-126; Corral Talciani, Hernán (2008). "Causalidad y Previsibilidad en la Responsabilidad Contractual". En Vargas Pinto, Tatiana (ed.): La relación de causalidad. Santiago: Universidad de los Andes, $N^{\circ} 15$, pp. 115 179, pp. 133-134; Vidal Olivares, Álvaro, "El incumplimiento de obligaciones con objeto fungible y los remedios del acreedor afectado”, en Guzmán Brito, Alejandro, El Código Civil de Chile (1855-2005), Santiago, LexisNexis, 2007, p. 540, n. 132. Nuestra posición es que, por lo menos para el caso de la indemnización de perjuicios consecuencial a la resolución del contrato, la indemnización de perjuicios recae únicamente sobre el id quod interest. Es decir, la indemnización de perjuicios en la resolución por incumplimiento tiene una naturaleza puramente reparatoria y no restitutoria. 
Así, en Cecinas La Preferida S.A con Comercial Salinak Limitada ${ }^{74}$, la empresa demandante pidió la resolución de un contrato de suministro de sal por incumplimiento de la entrega de un objeto distinto del pactado. La demandante solicitó como indemnización de perjuicios, a título de daño emergente, una cantidad de dinero ascendente al equivalente en valor de la mercancía elaborada con el insumo defectuoso, el costo de sustitución de otras mercancías, los costos de arriendo y pago de energía de los contenedores en que debían guardarse los productos afectados, a título de "daño emergente". No se demandó por lucro cesante. Nótese que la demandante no demandó lo que hubiere dejado de obtener si la mercancía que ella elaboraba hubiera estado en correcto estado (interés positivo). Se intentó, a través de la indemnización, borrar o corregir los daños producidos del incumplimiento de la demandada, como si no se hubiese celebrado el contrato (interés negativo). Si se hubiese solicitado el cumplimiento de la obligación, el acreedor debería reclamar una indemnización moratoria equivalente a lo que le hubiera significado la venta oportuna de las salchichas que producía. Imaginando que el valor de producción de las salchichas equivale a $\$ 50$, y se vendieran en el mercado a $\$ 120$, la ganancia del acreedor debería ser $\$ 70$. Pero, si por efecto del incumplimiento, el costo de colocación tardía en el mercado de las salchichas fuere de $\$ 30$, los daños moratorios equivalen a dicha suma. En cambio, si solicitara la resolución con indemnización de perjuicios, bajo el estándar del interés positivo (nuestra tesis), sus daños alcanzarían a $\$ 70$, esto es, lo que dejó de obtener por el cumplimiento íntegro de la prestación. Como puede verse, hay claras diferencias entre la indemnización moratoria a la indemnización compensatoria.

En otro caso, Inversiones Fabjanovic con Comercial Araucaria y otro ${ }^{75}$, se demandó de terminación de contrato de arrendamiento por no pago de rentas más indemnización de perjuicios. Por indemnización de perjuicios solicitó una cantidad de dinero equivalente a "los rubros de habilitación material del local arrendado al estado en que se encontraba al entrar en vigencia el contrato" más gastos por "desinsectación y desinfección”. Como se ve, el demandante solicitó colocar la mirada de los dańos al momento de perfeccionamiento del contrato (interés negativo), no al momento del incumplimiento (interés positivo). Si hubiese solicitado el acreedor el cumplimiento del contrato, la indemnización moratoria comprendería

74 Corte Suprema. 27 de julio de 2005. Rol No 5320-2003. "Cecinas La Preferida S.A con Comercial Salinak Limitada”. LegalPublishing Jurisprudencia Online, $\mathrm{N}^{\circ}$ LegalPublishing: 32452. Disponible en http://productos.legalpublishing.cl [fecha de visita 13 de octubre de 2010].

75 Primer Juzgado de Letras de Concepción. 20 de marzo de 2002. Rol N 5320-2003. "Inversiones Fabjanovic con Comercial Araucaria y otro". LegalPublishing Jurisprudencia Online, $\mathrm{N}^{\circ}$ LegalPublishing: 36562. Disponible en http://productos.legalpublishing.cl [fecha de visita 13 de octubre de 2010]. 
aquellos perjuicios derivados del retraso en el pago de la renta. Esto es, como se trata del incumplimiento en el pago de una suma de dinero, deberá demandarse como indemnización los intereses que se devenguen desde la constitución en mora del deudor, según el artículo 1559 (las rentas devengadas se cobran en sede de cumplimiento). En cambio, si se solicita la terminación del contrato, podría el acreedor demandar, bajo el prisma del interés positivo, el saldo de las rentas que quedaban hasta el fin del contrato, a título de indemnización de perjuicios ${ }^{76}$.

Un tercer ejemplo es el caso Inversiones Cerro Pan de Azúcar Ltda. con $\operatorname{Vegas}^{77}$, en que el demandante reconvencional solicitó como perjuicios patrimoniales resultantes de la inejecución del contrato aquellos derivados de los gastos en que incurrió para solicitar un crédito a una institución bancaria para financiar el contrato definitivo (interés negativo). No se demandó los perjuicios que resultaren de la apreciación económica sobre lo que le hubiere valido el cumplimiento del contrato de promesa (que se fundaría en el interés positivo). Pese a las dificultades de prueba, si solicitase el cumplimiento del contrato, habría que demandar los perjuicios que derivan del retraso en la celebración del cumplimiento del contrato definitivo. En cambio, si se solicitara la resolución del contrato, el interés positivo puede abarcar la diferencia por cambio del valor de mercado de la cosa objeto del contrato de promesa.

Como puede apreciarse de estas demandas, la indemnización tanto en caso de cumplimiento, como en caso de resolución son claramente distintas. Abordaremos entonces la situación que se podría producir cuando la indemnización en caso de cumplimiento sería monetariamente equivalente a la indemnización resolutoria.

\section{(4.3.3.) Casos en que el quantum de ambas indemnizaciones son mo- netariamente equivalentes}

Reconocemos que existen situaciones en que la indemnización de perjuicios moratoria en caso de cumplimiento puede monetariamente

76 Esto fue lo que precisamente se demandó en Sociedad Seguridad Valher Chile Ltda. con Servicio de Salud Talcahuano: Corte Suprema. 25 de marzo de 2009. Rol No 6856-2007. "Sociedad Seguridad Valher Chile Ltda. con Servicio de Salud Talcahuano". LegalPublishing Jurisprudencia Online, $\mathrm{N}^{\circ}$ LegalPublishing: 41793. Disponible en http://productos.legalpublishing.cl [fecha de visita 13 de octubre de 2010]. En este caso, la demandante solicitó la terminación del contrato de prestación de servicios más una indemnización compensatoria equivalente al total del precio que debía pagar la demandada en los meses que quedaban de contrato (interés positivo), a pesar de la resolución del contrato, con sentencia favorable de la Corte Suprema.

77 Corte de Apelaciones de Rancagua. 9 de julio de 2007. Rol N 1083-2006. "Inversiones Cerro Pan de Azúcar Ltda. con Vegas". LegalPublishing Jurisprudencia Online, $\mathrm{N}^{\circ}$ LegalPublishing: 36608. Disponible en http://productos.legalpublishing.cl [fecha de visita 13 de octubre de 2010]. 
coincidir a la indemnización por resolución bajo el criterio del interés positivo. Sin embargo, desde un punto de vista dogmático y práctico la situación sigue siendo diversa.

Imaginemos un contrato de compraventa de una cosa en que se incumple la obligación de entrega. En el daño al interés negativo habría que colocar al comprador en aquella situación si el contrato no se hubiese celebrado. Por tanto, en la práctica obtendrá restitución del precio (si lo pagó), e intentará probar el daño emergente y el lucro cesante que se le produjo por no haber celebrado el contrato. En el daño al interés positivo, también obtendrá restitución, pero la indemnización de perjuicios debería colocar al comprador en aquella posición como si el contrato se hubiese cumplido (el id quod interest), menos el valor de prestación (aestimatio rei).

Así planteadas las cosas, parece en abstracto haber una diferencia entre daño al interés positivo y negativo, pero no así entre la indemnización compensatoria y moratoria. Para concretar el ejemplo, entonces, introduciremos una variable: el objeto comprado se trata de un repuesto necesario para una máquina. Al aplicarlo a la esta, por defecto de aquel, la máquina se descompone y paraliza la producción de los bienes que ella elaboraba. En el daño al interés negativo será necesario entonces resarcir el daño sufrido, cual es el costo de reparación de la máquina que se estropeó. En cambio, si la óptica se coloca en el dańo al interés positivo, el daño mira a la inejecución del contrato. Por lo pronto, las mercancías que se hubieren estropeado y lo que dejó de obtener por ellas sumadas a la falta de producción.

Ahora, si el acreedor solicita el cumplimiento del contrato, la cuestión cambia. Según nuestra tesis, el acreedor podrá obtener el cumplimiento de la obligación (el repuesto) más los daños que la mora hubiere producido. Entonces, ¿qué diferencia existe entre esa indemnización moratoria y la indemnización compensatoria? Parece ser que en estos casos la indemnización moratoria en caso de cumplimiento puede ser idéntica en términos monetarios a la compensatoria en caso de resolución.

Si bien monetariamente los daños pueden ser equivalentes (ambas no consideran la reparación misma de la máquina, en principio), la diferencia se sigue justificando precisamente en el sistema de acumulación de remedios que plantea tanto la pretensión de cumplimiento como la resolución del contrato en el artículo 1489.

En la pretensión de cumplimiento, el contrato mantiene vigencia, y por tanto el acreedor se verá obligado a pagar el precio, si es que no lo ha pagado. En cambio, en la resolución, el acreedor se libera de cumplir por su parte lo pactado, o bien, si pagó obtendrá restitución.

La opción es relevante puesto que al acreedor puede ya no interesarle el cumplimiento de la obligación, por diferentes razones (por pérdida de la confianza, porque efectuó una operación de reemplazo, porque perdió 
interés en ella, etc.). Ante ello elegirá la opción resolutoria. De esta manera, el acreedor cumplirá su interés a través de la liberación del contrato, la restitución, si es que ella es procedente, y la indemnización de los dańos que comprende su id quod interest.

$\mathrm{Si}$, en cambio, le interesa mantener el contrato a pesar de un incumplimiento puntual (por ejemplo, se trata de una convención de tracto sucesivo o de ejecución diferida), podrá pedir el cumplimiento y la indemnización moratoria, conservando sus propias obligaciones y también las del deudor.

En conclusión, la funcionalidad de los remedios es claramente distinta y satisfacen el interés del acreedor en la medida que este estime cuál es el remedio más adecuado a su pretensión.

\section{CONCLUSIONES}

De todo lo anterior podemos enunciar las siguientes conclusiones:

(1a) Existen dos formas de entender qué comprende el perjuicio contractual derivado del incumplimiento resarcible a través de la indemnización de perjuicios: el interés positivo o de cumplimiento y el interés negativo o de confianza. La indemnización de perjuicios que cubre el daño al interés positivo tiene por objeto colocar al acreedor en una situación similar a si se hubiese cumplido el contrato; la del interés negativo tiene por objeto colocar al acreedor en una posición similar a si el contrato no se hubiera celebrado.

(2a) La distinción entre daño al interés positivo y daño al interés negativo es aplicable a la indemnización de perjuicios consecuencial a la resolución por incumplimiento establecida en el 1489 del Código Civil. En Chile, al igual que en el Derecho Comparado, se puede plantear la discusión si lo indemnizable en este supuesto es o el interés positivo o el interés negativo ya que la resolución acarrea como efecto la extinción de la relación obligatoria, pero, además, legalmente se concede una acción de perjuicios.

(3a) En doctrina comparada la discusión no es pacífica. En los sistemas de tradición europea continental tiende a reducirse el planteamiento del problema a los efectos retroactivos que la resolución acarrea y a una supuesta renuncia al interés positivo en caso de opción por la resolución. También se atiende al principio de la fuerza obligatoria del contrato y si este trasciende, o no, a la indemnización una vez que el contrato ha perdido eficacia.

(4a) No existe en el Código Civil chileno una disposición cuyo texto imponga una u otra solución. Tanto los artículos 1556 y 1558, siguiendo su tenor literal, pueden interpretarse tanto a favor de las doctrinas 
que propugnan la indemnización del interés positivo, como aquellas que son partidarias al interés negativo.

(5a) Una indagación sobre la función de la resolución y, concretamente, sobre la indemnización de perjuicios que ella conlleva conduce a sostener que se trata de un instrumento destinado a la protección no solo del patrimonio del acreedor, sino de protección del crédito. Por ello, la indemnización de los perjuicios resolutorios debe ser medida bajo el prisma del interés positivo. El resarcimiento del interés de expectativa se complementa con el efecto extintivo/restitutorio de la resolución del contrato, que tiene por función la protección del patrimonio.

(6a) La aceptación del interés positivo no resulta afectada por el argumento de que la resolución opera con efecto retroactivo, ya que este efecto no se produce respecto de la indemnización de perjuicios. La estructura de la resolución por incumplimiento puede asemejarse a los sistemas modernos de resolución de contrato que la configuran como una liquidación de las relaciones mutuas entre acreedor y deudor, protegiendo el interés positivo a través de la indemnización.

(7a) También debe rechazarse el argumento que establece que la resolución constituye una renuncia al interés positivo, toda vez que este se funda en la desaparición retroactiva del contrato, y de aceptarse haría, en los casos en los que no procede estructuralmente la posibilidad de cumplimiento, que el deudor incumplidor determinara qué interés se indemniza.

(8a) La indemnización de perjuicios fundada en el interés positivo en caso de resolución de contrato se diferencia de aquella que deriva de la pretensión de cumplimiento, toda vez que esta es moratoria y aquella compensatoria. Incluso en los casos en los que pudiera darse una coincidencia monetaria entre ambas indemnizaciones, subsiste la diferencia de que con el cumplimiento se mantiene la vigencia del contrato y sus obligaciones para ambas partes, mientras que con la resolución dichas obligaciones se extinguen.

\section{BIBLIOGRAFÍA CITADA}

- Abeliuk Manasevich, René (2005). Las obligaciones. 4a ed. Santiago: Editorial Jurídica de Chile.

- Alessandri Rodríguez, Arturo, Somarriva Undurraga, Manuel y Vodanovic Haklicka, Antonio (2001). Tratado de las obligaciones. Santiago: Editorial Jurídica de Chile.

- Alonso Traviesa, María Teresa (2006). El problema de la concurrencia de responsabilidades. Santiago: LexisNexis. 
- Atiyah, P.S. (2001). "Contracts, Promises and the Law of Obligations". En Atiyha, P.S.: Essays on contract. New York: Oxford University Press, pp. 10-56.

- Atryah, P.S. (2001). "Excecutory Contracts, Expectation Damages, and the Economic Analysis of Law". En Atiyah, P.S.: Essays on contracts. New York: Oxford University Press, pp. 150-178.

- Atiyah, P.S. (2003). Promises, morals and law. New York: Oxford University Press.

- Ativah, P.S. (2003). The rise and fall of freedom of contracts. New York, Oxford University Press.

- Baraona González, Jorge (2008). "La acción redhibitoria como acción de nulidad”. En Guzmán Brito, Alejandro (editor): Estudios de Derecho Civil III. Santiago: LegalPublishing, pp. 659-669.

- Baraona González, Jorge (1997). "Responsabilidad contractual y factores de imputación de daños: apuntes para una relectura en clave objetiva". Revista Chilena de Derecho, vol. $24 \mathrm{~N}^{\circ}$ 1, Santiago, pp. 151-177.

- Barnett, Randy (1984). "Contract Scolarship and the Reemergence of Legal Phylosophy". Harvard Law Review, vol. 97, pp. 1223-1245.

- Barrientos Zamorano, Marcelo (2008). Daños y deberes en las tratativas preliminares de un contrato. Santiago: LegalPublishing.

- Barros Bourie, Enrique (2008). "Finalidad y alcance de las acciones y los remedios contractuales". En GuzMán Brito, Alejandro (editor). Estudios de Derecho Civil III. Santiago: Legal Publishing, pp. 403-428.

- Barros Bourie, Enrique (2007). Tratado de responsabilidad extracontractual. Santiago: Editorial Jurídica de Chile.

- Birmingham, Robert, (1969). "Breach of contract, damage measure, and economic efficiency". Rutgers Law Review, N² 24, pp. 273-292

- Bustamante Salazar, Luis, (2005). "Autonomía del equivalente pecuniario o su integración dentro de la indemnización de daños y perjuicios”. En Varas Braun, Juan Andrés y Turner Saelzer, Susan (coordinadores). Estudios de Derecho Civil. Santiago: LexisNexis, pp. 105-126.

- Calabresi, Guido y Melamed, Douglas (1972). "Property Rules, Liability Rules and inalienabilty: one view of the cathedral". Harvard Law Review, $\mathrm{N}^{\circ} 85$, pp. 1089-1128.

- Claro Solar, Luis (1979). Explicaciones de derecho civil chileno y comparado. $2^{\mathrm{a}}$ ed. Santiago: Editorial Jurídica de Chile.

- Corral Talciani, Hernán (2008). "Causalidad y Previsibilidad en la Responsabilidad Contractual”. En Vargas Pinto, Tatiana (editora): La relación de causalidad. Santiago: Universidad de los Andes, $\mathrm{N}^{\circ} 15$, pp. 115-179. 
- Cousiño Mac-Iver, Luis (1926). De la condición suspensiva (memoria de prueba). Santiago: Universidad de Chile, pp. 96-97.

- Craswell, Richard (2000). "Against Fuller and Perdue". University of Chicago Law Journal, N 67, pp. 99-162.

- Craswell, Richard (2006). "Expectation Damages and Contract Theory Revisited”. Stanford Public Law Working Paper No. 925980. Stanford Law and Economics Olin Working Paper No. 325. Disponible en: http://ssrn. com/abstract $=925980$ [fecha de visita 13 de octubre de 2010].

- De Cupis, Adriano (1975). El daño. Traducción de Ángel Martínez Serrión. Barcelona: Bosch.

- Dell'Aquila, Enrico (1981). La resolución del contrato bilateral por incumplimiento. Salamanca: Ediciones Universidad de Salamanca.

- Delvaux, Paul-Henry (2001). "Les effets en droit belge de la résolution des contrats pour inexécution”. En Fontaine, Marcel y Viney, Geneviève (editores). Les sanctions de inexécutions des obligations contractuelles. Paris: L.G.D J, pp. 669-697.

- Di Majo, Adolfo (2003) Problemi e método del diritto civile. La tutela civile dei diritti. Milano: Giuffrè editore.

- Díez-Picazo, Luis (2008). Fundamentos del Derecho Civil Patrimonial. Madrid: Civitas.

- Espinar Lafuente, Francisco (1969). "Resolución e indemnización en las obligaciones recíprocas". En Fuenmayor Champín, Amadeo y Sancho Rebudilla, Francisco (editores): Estudios de Derecho Civil. En honor del profesor Castán Tobeñas. Pamplona: Ediciones Universidad de Navarra, t. 2, pp. 113-163.

- Farnsworth, E. Allan, (2004). Contracts. $4^{\mathrm{a}}$ ed. New York: Apen Publishers.

- Fried, Charles (1996). La obligación contractual. El contrato como promesa. Traducción de Ruiz-Tagle Vial, Santiago: Editorial Jurídica de Chile.

- Friedmann, Daniel (1989). "The Efficient Breach Fallacy". The Journal of Legal Studies, vol. $18 \mathrm{~N}^{\circ}$ 1, pp. 1-24.

- Friedmann, David (1989). "An economic analysis of alternative damage rules for breach of contract”. Journal of Law \& Economics. $\mathrm{N}^{\circ} 32$, pp. 281-310.

- Fueyo Laneri, Fernando (2004). Cumplimiento e incumplimiento de las obligaciones. $3^{\text {a }}$ ed. Santiago: Editorial Jurídica de Chile.

- Fuller, Lon (1941). "Consideration and form". Columbia Law Review, No 41, pp. 799-824.

- Fuller, Lon y Perdue, William (1936-1937). "The reliance interest in contract damages". Yale Law Journal, vol. 46, pp. 52-96 y 373-420.

- Gatica Pacheco, Sergio (1959). Aspectos de la indemnización de perjuicios por incumplimiento de contrato. Santiago: Editorial Jurídica de Chile. 
- Genicon, Thomas (2007). La resolution du contrat pour inexécution. Paris: L.G.D.J.

- Gilmore, Grant (1995). The death of contract. 2a ed. Columbus: The Ohio State University Press.

- Guzmán Brito, Alejandro (2007). "Sobre la relación entre las acciones de saneamiento de los vicios redhibitorios y las acciones comunes de indemnización, con especial referencia a su prescripción". Revista Chilena de Derecho Privado, N 9, pp. 95-120.

- Hudec, Robert (1984). "Restating the 'reliance interest". Cornell Law Review, vol. 67, pp. 704- 734.

- Ibáñez, Carlos (2006). Resolución por incumplimiento. $1^{\mathrm{a}}$ reimpresión. Buenos Aires: Astrea.

- Kelly, Michael (1992). "The phantom reliance interest in contract damages". Wisconsin Law Review, 1992, pp. 1755-1846.

- Kronman, Anthony (1978). "Specific Performance". University of Chicago Law Review, vol. 45, pp. 351-382.

- Laithier, Ives-Marie (2007). Etude comparative des sanctions de l'inexécution du contrat. Paris: L. G.D.J.

- Laithier, Yves-Marie (2005). "Comparative Reflections on the French Law of Remedies for Breach of Contract". En Cohen, Nili y Mckendrick, Ewan (editores): Comparative remedies for Breeach of Contract. Portland: Hart Publishing, pp. 103-122.

- Lando, Ole y Beale, Hugh (2000). Principles of European Contract Law. Cambridge: Kluwer Law International.

- Larenz, Karl (1958). Derecho de obligaciones. Traducción de Santos Briz, Jaime, Madrid: Editorial Revista de Derecho Privado, t. 1, vol. 2 .

- Leitzel, Jim, (1989). "Reliance and contract breach". Law and contemporary problems, vol. 52, pp. 87-105.

- Leloutre, Amdée (1907). "Estudio sobre la retroactividad de la condición". Revista de Derecho y Jurisprudencia, t. 5, I parte, pp. 161-175.

- Macaulay, Stewart (1991). "The reliance interest and the world outside the law schools' doors". Wisconsin Law Review, 1991, pp. 247-291.

- Markesinis, Basil, Unberath, Hannes y Johnston, Angus, (2006). The german law of contract. Portland: Hart Publishing, 2006.

- Mélich-Orsini, José (2007). La resolución del contrato por incumplimiento. $3^{\mathrm{a}}$ ed. Caracas: Academia de Ciencias Políticas y Sociales.

- Messineo, Francesco (1955). Manual de Derecho Civil y Comercial. Buenos Aires: Ediciones Jurídicas Europa-América.

- Morales Moreno, Antonio Manuel (2006). "El derecho a la reparación o sustitución de la cosa no conforme y la naturaleza de la 
obligación del vendedor”. En Morales Moreno, Antonio Manuel: La modernización del derecho de obligaciones, Madrid: Aranzadi

- Palazón Garrido, María Luisa, (2009). "La resolución del contrato como medio de tutela en caso de incumplimiento". En Sánchez Lorenzo, Sixto (coordinador): Derecho contractual comparado. Madrid: Civitas, pp. 769-820.

- Pantaleón, Fernando (1989). "Resolución por incumplimiento e indemnización". Anuario de Derecho Civil, vol. 42 N 4, pp. 11431168.

- Pantaleón, Fernando (1993). "Las nuevas bases de la responsabilidad contractual”. Anuario de Derecho Civil, vol. 46 NN$^{\circ} 4$, 1993, pp. 1719-1746.

- Peñailillo Arévalo, Daniel (2003). Obligaciones. Santiago: Editorial Jurídica de Chile.

- Pinna, Andrea (2007). La mesure du préjudice contractuel. Paris: L.G.D.J.

- Pizarro Wilson, Carlos (2008). "Hacia un sistema de remedios al incumplimiento contractual". En Guzmán Brito, Alejandro (editor): Estudios de Derecho Civil III. Santiago: LegalPublishing, pp. 398-400.

- Pizarro Wilson, Carlos (2004). "Notas críticas sobre el fundamento de la fuerza obligatoria del contrato. Fuentes e interpretación del artículo 1545 del Código Civil Chileno". Revista Chilena de Derecho, vol. $32 \mathrm{~N}^{\circ}$ 2, pp. 225-237.

- Posner, Richard (2007) Economic Analysis of Law. New York: Wolkers Kluwer.

- Rakoff, Todd, (1991). "Fuller and Perdue's: the reliance interest as a work of legal scholarship". Wisconsin Law Review, 1991, pp. 203-246.

- Ramos Pazos, René (2008). De las obligaciones. 3a ed. Santiago: LegalPublishing.

- Segura Riveiro, Francisco (2007). "El interés indemnizable en las hipótesis de responsabilidad precontractual”. En Corral Talciani, Hernán y Rodríguez Pinto, María Sara (coordinadores). Estudios de Derecho Civil II. Santiago: LexisNexis, pp. 345-362.

- Serinet, Yves-Marie (2001). "L'effet rétroactif de la résolution pour inexécution en droit français". En Fontaine, Marcel y Viney, Geneviève: Les sanctions de l'inexécution des obligations contractuelles, PARIS: L.G.D.J., pp. 589-668.

- Shavell, Steven (1980). "Damage measures for breach of contract". The Bell Journal of Economics, vol. $11 \mathrm{~N}^{\circ}$ 2, pp. 466- 490.

- Slawson, W. David (1990). "The role of reliance in contracts damages". Cornell Law Review, vol. 76, pp. 197-237.

- Smith, Stephen (2001). "The Reliance Interest in Contract Damages' and the Morality of Contract Law", Issues in Legal 
Scholarship. Disponible en http://www.bepress.com/ils/issl/artl, en línea [fecha de visita 13 de octubre de 2010].

- Treitel, G. H. (1988). Remedies for breach of contract. A comparative account. New York: Oxford University Press.

- Treitel, G. H. (1995). The law of contract. London: Sweet \& Maxwell.

- Trigo Represas, Félix y López Meza, Marcelo (2005) Tratado de la responsabilidad civil, Buenos Aires: La ley.

- Trimarchi, Pietro (2002). "Interesse positivo e interesse negativo nella risoluzione del contratto per inadempimento". Rivista di diritto civile, vol. $48 \mathrm{~N}^{\circ}$ 5, pp. 637-648.

- VIal del Río, Victor (2007). Manual de las obligaciones en el Código Civil chileno. $2^{\mathrm{a}}$ ed. Santiago: Editorial Biblioteca Americana.

- Vidal Olivares, Álvaro (2007). "El incumplimiento de obligaciones con objeto fungible y los remedios del acreedor afectado". En Guzmán Brito, Alejandro: El Código Civil de Chile (1855-2005), Santiago: LexisNexis, pp. 495-550.

- Weinrib, Ernest J. (2002). "Corrective justice in a nutshell". University of Toronto Law Journal, vol. 52, pp. 349-356.

- Weinrib, Ernest J. (1995). The idea of private law. Cambridge: Harvard University Press.

- Zimmermann, Reinhard (1996). The law of obligations. New York: Oxford University Press.

- Zimmermann, Reinhard (2005). The new german law of obligations. New York: Oxford University Press. 